\title{
Design and manufacturing of morphing fan blades for experimental investigations in a cascaded wind tunnel
}

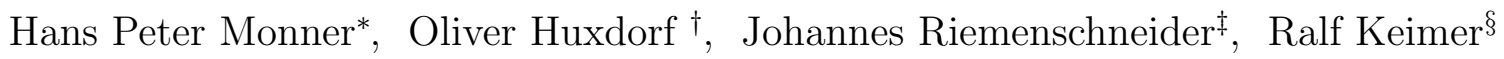 \\ German Aerospace Center (DLR), Braunschweig, Niedersachsen, D-38108, Germany
}

Within this paper shape variable compressor blades for jet engines using piezoelectric composite actuators attached to the blade's suction and pressure sides are investigated. By applying a voltage to these actuators it is possible to increase and to decrease the blade stagger angle by changing the camber angle. This study is about the engineering process and about the first results of a cascaded wind tunnel experiment.

\section{Nomenclature}

$d \quad$ thickness of the profile, $\mathrm{mm}$

$f \quad$ relative deviation, $\%$

$l_{c l} \quad$ chord length, $\mathrm{mm}$

$l_{s d} \quad$ length in spanwise direction, $\mathrm{mm}$

$m$ slope in, $\mathrm{mm} /{ }^{\circ}$

$s \quad$ standard deviation, $\mathrm{mm}$

$t \quad \mathrm{t}$ value for the $\mathrm{t}$-distribution

$t_{e} \quad$ blade spacing, $\mathrm{mm}$

$u$ displacement in, $\mathrm{mm}$

$v \quad$ inflow velocity, $\mathrm{m} / \mathrm{s}$

$x \quad$ coordinate $\mathrm{x}, \mathrm{mm}$

E Young's modulus, $\mathrm{N} / \mathrm{mm}^{2}$

$F$ force, $\mathrm{N}$

$P \quad$ coordinates of a point, $\mathrm{mm}$

$P_{C} \quad$ confidence level, $\%$

$U$ electric voltage, $\mathrm{V}$

$\alpha \quad$ angle of attack, ${ }^{\circ}$

$\delta$ difference of the displacements, $\mathrm{mm}$

$\varepsilon_{0} \quad$ free strain

$\kappa$ blade angle, ${ }^{\circ}$

$\lambda$ stagger angle, ${ }^{\circ}$

$\varphi \quad$ camber angle, ${ }^{\circ}$

\footnotetext{
${ }^{*}$ Head of the Department of Adaptronics, Institute of Composite Structures and Adaptive Systems, Lilienthalplatz 7, 38108 Braunschweig, Germany; Hans.Monner@dlr.de, and AIAA Member Grade for first author

${ }^{\dagger}$ Scientist, Institute of Composite Structures and Adaptive Systems, Lilienthalplatz 7, 38108 Braunschweig, Germany; Oliver.Huxdorf@dlr.de, AIAA Member Grade for second author

${ }^{\ddagger}$ Deputy Head of the Department of Adaptronics, Institute of Composite Structures and Adaptive Systems, Lilienthalplatz 7, 38108 Braunschweig, Germany; Johannes.Riemenschneider@dlr.de, AIAA Member Grade for third author

§Scientist, Institute of Composite Structures and Adaptive Systems, Lilienthalplatz 7, 38108 Braunschweig, Germany; Ralf.Keimer@dlr.de, AIAA Member Grade for third author
} 


\section{Introduction}

The corresponding paper deals with the engineering of morphing compressor blades of aircraft jet engines and their experimental investigations in a cascaded wind tunnel with a two-dimensional flow. The motivation of this research is given by the fact that current engines only work with fixed blade geometries. But in different parts of the flight the engine operates at design (cruise) and off-design (start, climb, descent and landing) conditions. Consequently with a fixed blade geometry the engine has to work over a wide range of boundary conditions. As a consequence the development of a jet engine always results in a compromise between design and off-design operation and the maximum achievable efficiencies at design operation are limited by off-design requirements.

With shape adaptive compressor blades it is possible to adapt the engine to different flow conditions in several phases of the flight. This technology has the potential to maximize the propulsive efficiency, to reduce the fuel consumption and consequently to lower the travelling expenses. Furthermore it could be possible to decrease the necessary start distance due to the increased propulsive efficiency.

The structural feasibility of morphing compressor blade concepts were shown in different studies. Exemplary some concepts are suggested in the following. Müller and Laweren $z^{1}$ present three concepts for use in blades with a chord length of $l_{c l}=200 \mathrm{~mm}$, a length in spanwise direction of $l_{s d}=200 \mathrm{~mm}$ and a maximum thickness of $t=24 \mathrm{~mm}$. In the first concept the morphing structure is realized by using a kinematic chain mechanism as described in Monner ${ }^{4}$ to adapt the structure. The second concept uses shape memory alloy wires to apply bending moments in the skin. A hyperelastic material with integrated pressurized channels in the suction and in the pressure side were used in the third concept. Müller ${ }^{2}$ and Müller and Lawerenz $z^{3}$ describe these concepts partially in more detail. Van de Kamp $p^{5}$ presents another morphing concept with macro fiber composite actuators (MFC) attached to the suction and pressure side of the skin. By applying a voltage to these actuators it is possible to twist the blades. The blade geometry has a chord length of $l_{c l}=77.4 \mathrm{~mm}$, a length in spanwise direction of $l_{s d}=111 \mathrm{~mm}$ and a maximum thickness of $d_{\max }=3.56 \mathrm{~mm}$. While the first three concepts are suitable for relative thick profiles the latter one is characterized for use in thin blade geometries.

Because of the limited space in the given blade geometry this study focusses on the development of shape variable compressor blades based on piezoceramic actuators for experimental investigations in a cascaded wind tunnel. In comparison to the study of Van de Kamp ${ }^{5}$ the wind tunnel experiment and the modified blade profile require a redesign of the blades with respect to the aerodynamic requirements in the wind tunnel. In the first part of the paper the engineering and manufacturing process are described. The second part of the paper deals with the first experimental results of the cold geometry by applying a voltage to the actuators. Finally the experimental results of the wind tunnel experiment are presented. The focus is on the blade deformations under aerodynamic loads.

\section{Design}

\section{A. Design requirements}

The main task to develop the adaptive compressor blades is to integrate the morphing concept in a given thin blade profile. The blade profile is given by the Institute of Jet Propulsion and Turbomachinery of the Technical University of Braunschweig and is optimized for the investigations in the used cascaded wind tunnel. The profile is not equivalent with a NACA profile or similar.

The blade profile is shown in figure 1. It has a chord length of $l_{c l}=100 \mathrm{~mm}$ and a maximum thickness of $d_{\max }=3.85 \mathrm{~mm}$. In non deformed ideal state the blade inlet angle on the leading edge and the blade outlet angle on the trailing edge are $\kappa_{1} \approx 35.7^{\circ}$ and $\kappa_{2} \approx 7.5^{\circ}$. This results in a camber angle of $\varphi \approx 43,2^{\circ}$. Caused by the wind tunnel test section width in spanwise direction the compressor blades are $l_{s d}=200 \mathrm{~mm}$ long. For the experimental investigations five identical blades with a blade spacing of $t_{e}=80 \mathrm{~mm}$ and a stagger angle of $\lambda=16^{\circ}$ are mounted to the wind tunnel.

The shape adaptive compressor blades were developed for experimental investigations in a cascaded wind tunnel. For this application the following essential requirements and aspects were identified:

- The goal of the morphing structure is to change the blade stagger angle by adapting the blade camber angle. Therefore the required deformed shapes are characterized by a non deformed leading edge while the deformation increases continuously to the trailing edge.

2 of 13

American Institute of Aeronautics and Astronautics 


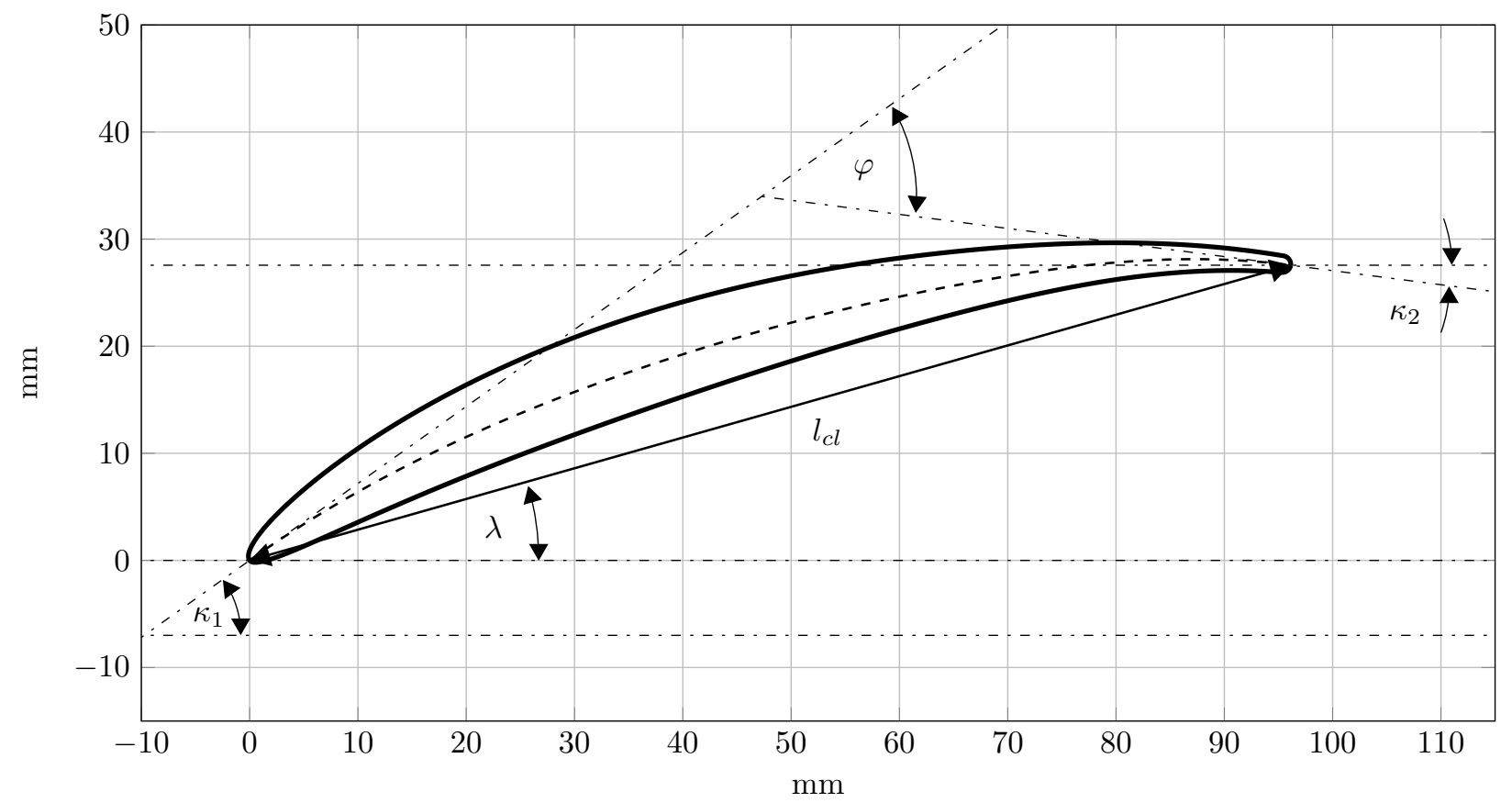

Figure 1: Dimensions of the ideal blade profile

- As the characteristic parameter for the shape variable blades the camber angle variation is identified. A minimal blade deformation of $\Delta \varphi_{ \pm}=1^{\circ}$ in each direction is required. Thus an overall deformation of $\Delta \varphi_{t o t}=2^{\circ}$ is necessary.

- For aerodynamic investigations a cascaded wind tunnel is used. This wind tunnel setup is characterized by a two-dimensional plane flow. To generate these conditions the blades must have a continuous profile geometry in spanwise direction for each deformed shape as well as for the non-deformed shape.

- Another important point is to prevent the friction between the wind tunnel walls and the blade front sides to not hinder the free deformation of the blade. The friction would hamper the free deformation of the blade.

- The pressure distributions for different angles of attack will be measured in a cascaded wind tunnel experiment. For this investigations two blades instrumented with 15 pressure taps are needed (one blade with pressure taps at the suction side and one blade with pressure taps at the pressure side)

- Caused by the fact that five blades were used a reproducible manufacturing process has to be select.

\section{B. Actuator selection}

To develop the shape adaptive compressor blades different piezoceramic actuator types are available. For this application the actuators type MFC M8528-P1 (at the following section with the index 28) and MFC M8557-P1 (at the following section with the index 57) using the $\mathrm{d}_{33}$ effect of the Smart Material GmbH are selected. These types are distinguished by their piezoceramic fiber layout and the resulting advantage of an actuation in only one direction. Transversely to the fiber orientation the actuating effect is minimized. Consequently with these types the requirement of a constant profile geometry in spanwise direction for each deformation shape can be full filled. According to the manufacturing specifications the actuators have a free strain of $\varepsilon_{0}=1.8 \cdot 10^{-6}$ and a blocking force of $F_{B_{28}}=454 \mathrm{~N}$ respectively $F_{B_{57}}=923 \mathrm{~N}$. 


\section{Defining a valid Young's modulus}

In this section it is the goal to define a valid Young's modulus for the final five compressor blades. Therefore a test blade with $l_{s d}=35 \mathrm{~mm}$ and piezoceramic actuators attached to the suction and pressure side are manufactured. By applying a voltage to these actuators subsequently the test blade displacement at the trailing edge is investigated. With the measured displacement the maximum permitted blades Young's modulus can be approximated. The test blade is shown in figure 2.

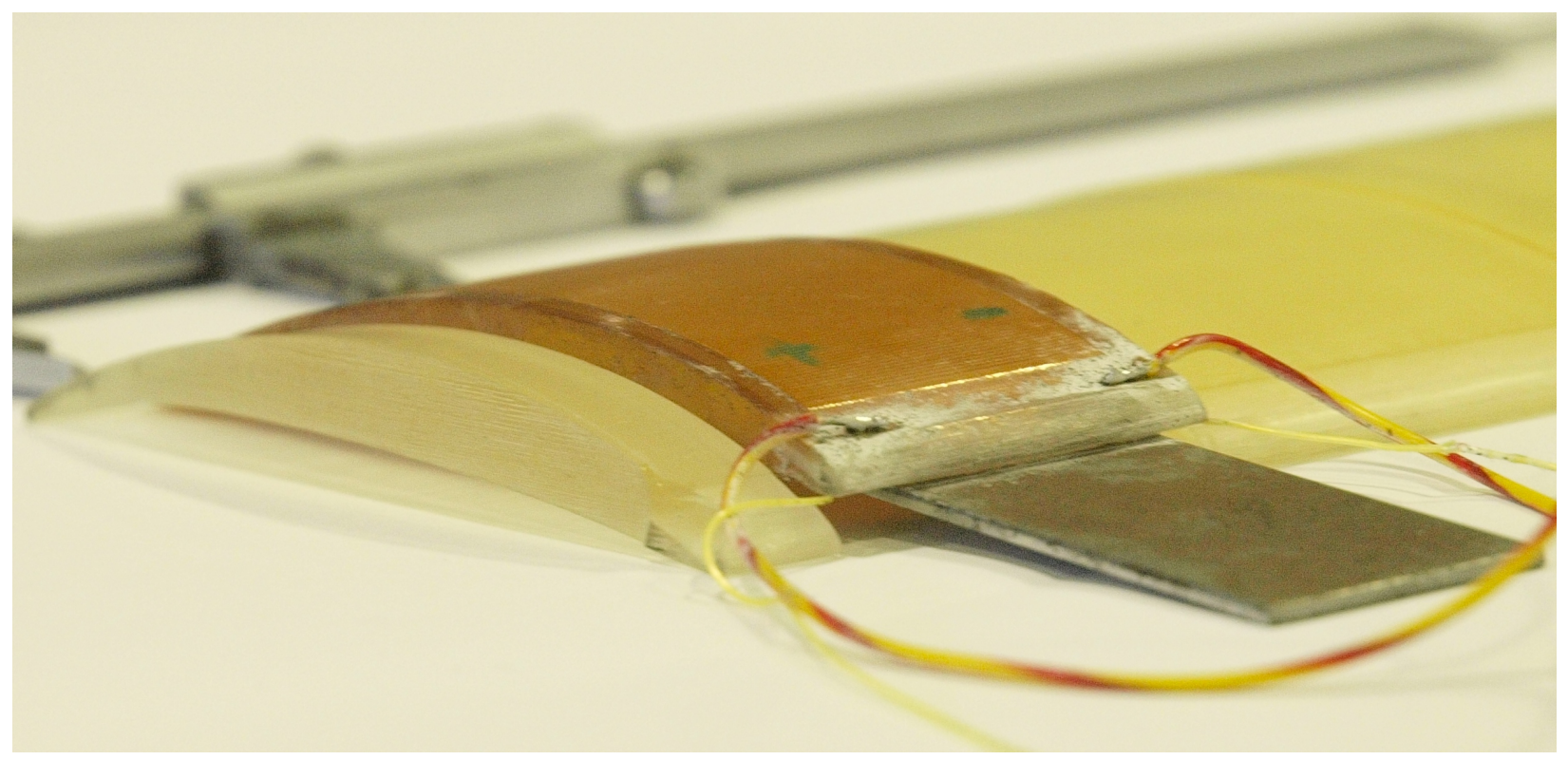

Figure 2: Test blade with a sheet steel glues to the leading edge

The test blade was built in a three dimensional rapid prototyping manufacturing process (Poly Jet Modelling) using photopolymeric materials. The used material (FullCure720) has a Young's modulus of $E_{F C 720}=2870 \mathrm{~N} / \mathrm{mm}^{2}$. By using an epoxy adhesive the actuators MFC8557-P1 type from the Smart Material Corp. are attached to the suction and to the pressure side of the blade. For the fixation a short sheet metal is attached near to the leading edge. An additional function of the sheet metal is to stiffen the leading edge because a non deformable leading edge is required.

For the experimental setup the test blade is clamp vertically. For the investigations three different shape conditions are defined. The first condition is named reference condition and represents the non deformed blade profile without an applied voltage at the blades suction and pressure side. The second and the third conditions represent the maximum deformed blade profiles with a voltage of $U_{S S}=1500 \mathrm{~V}$ at the suction side and with a voltage of $U_{P S}=-500 \mathrm{~V}$ at the pressure side and with a voltage of $U_{S S}=-500 \mathrm{~V}$ and $U_{P S}=1500 \mathrm{~V}$. At the following sections these two deformed conditions will be referred as first and second deformed condition.

To characterize and to measure the deformed blade profile an optical measurement system called ARAMIS from the GOM mbH is used. By using the stereo camera technology this system makes a three-dimensional digital image of the different shape conditions. This system divides the imaged surface in facets and assigns every facet to one measuring point with three spatial coordinates. In figure 3 the results of the measured points of the test blade in its symmetry plane are shown. On the left side the blade is mounted and on the right side the trailing edge is located.

To calculate the blade outlet angle $\kappa_{2}$ the average slope of the line between the last and the third last point at the trailing edge at eleven cross sections was determined for each condition. As next step the slope difference between the reference shape and the deformed shapes were calculated. Between the reference condition to the first deformed condition a blade outlet angle variation of $\Delta \kappa_{2_{1}}=1,99^{\circ}$ and to the second deformed condition a blade outlet angle variation of $\Delta \kappa_{2_{2}}=-1.92^{\circ}$ was identified. In summary this results in a camber angle variation of $\Delta \varphi=\left|\Delta \kappa_{2_{1}}\right|+\left|\Delta \kappa_{2_{2}}\right|=3,91^{\circ}$.

With the Young's modulus of the used photopolymeric material $E_{F C 720}=2870 \mathrm{~N} / \mathrm{mm}^{2}$, the determined camber angle variation of the test blade $\Delta \varphi_{\min }=3.91^{\circ}$, the required camber angle variation of $\Delta \varphi=2^{\circ}$ 


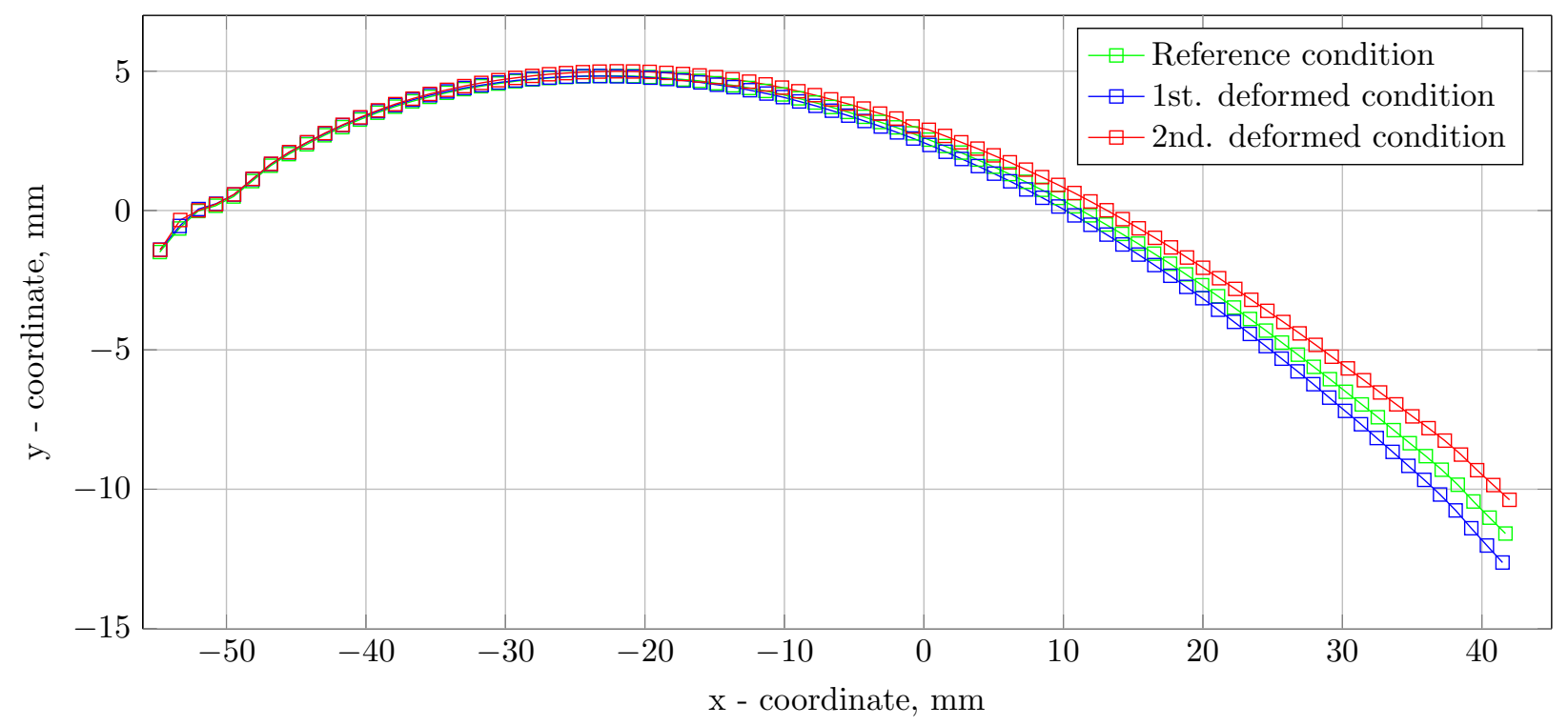

Figure 3: Deformed suction side of the test blade

and an assumed linear relationship between the camber angle variation and the elasticity the maximum allowable Young's modulus of the blade material can be estimate with the following Eq. (1):

$$
\begin{aligned}
E_{\text {max }} & =E_{F C 720} \frac{\Delta \varphi_{\text {exp }}}{\Delta \varphi_{\min }} \\
E_{\max } & =2870 \frac{\mathrm{N}}{\mathrm{mm}^{2}} \cdot \frac{3.91^{\circ}}{2^{\circ}} \\
E_{\max } & \approx 5611 \frac{\mathrm{N}}{\mathrm{mm}^{2}}
\end{aligned}
$$

Usually metallic materials have higher Young's modulus than required in Eq. (2). Materials with a Young's modulus smaller than $E_{\max }$ normally are plastics. Therefore in table 1 some plastics suited to the requirements are listed. When selecting the final blade material it is important that the Young's modulus is not too low. Otherwise the blades deform too much under aerodynamic loads.

\section{Defining the material and the manufacturing process}

The selection of the final blade material is directly related to the selection of the manufacturing process. In this study milling and manual lamination of composite structures were investigated as alternatives in comparison to the rapid prototyping process. The good reproducibility, the ability to fabricate undercuts, the high quality of the build surfaces and a short production time for the five blades finally leads to the selection of the rapid prototyping process. In contrast to the test blade material the final structure was manufactured with a material called Vero Gray - FullCure850 with a higher Young's modulus (see table 1).

In figure 4 one of the blades at different manufacturing stages is shown. To stiffen the blade's leading edge a steel profile with a width of $b_{\text {steel }}=8 \mathrm{~mm}$, a height of $h_{\text {steel }}=2 \mathrm{~mm}$ and a length of $l_{\text {steel }}=260 \mathrm{~mm}$ was glued with a two component adhesive into a shaft near to the leading edge. As next step two piezoceramic actuators type MFC8528-P1 with an active width of $b_{a c t}=28 \mathrm{~mm}$ and two actuators type MFC8557-P1 with an active width of $b_{a c t}=57 \mathrm{~mm}$ were integrated in a cavity on the suction and pressure side. The wider actuators are located at the middle section of the blade, the smaller actuators at the outer sections. After the actuators have been attached the blades surfaces are not as smooth as required for a wind tunnel experiment. Therefore the gaps were filled up manually with a mounting adhesive called Pattex ONE FOR ALL of the Henkel AG \& Co. KGaA. 
Table 1: Young's moduli of selected plastics

\begin{tabular}{|l|c|}
\hline Material & Young's modulus in $\left[\mathrm{N} / \mathrm{mm}^{2}\right]$ \\
\hline Thermoplastics according to Wittel et al. \\
\hline Polyethylen (PE-HD) & 1000 \\
\hline Polyvinylchlorid (PVC-U) & 3000 \\
\hline Polytetraflourethylen (PTFE) & 410 \\
\hline Polyoxymethylen (POM) & 2800 \\
\hline Polyamid (PA66) & $1600 \ldots 2800$ \\
\hline Photopolymers according to Objet ${ }^{9}$ \\
\hline FullCure720 \\
\hline Vero Gray - FullCure850 & 2870 \\
\hline Duroplasts according to Wittel et al. ${ }^{6}$ \\
\hline PUR - Integral foam & 3000 \\
\hline Polyester resin (UP) & $350 \ldots 600$ \\
\hline Elastomer according to Wittel et al. ${ }^{6}$ \\
\hline Silicone rubber & 3500 \\
\hline
\end{tabular}

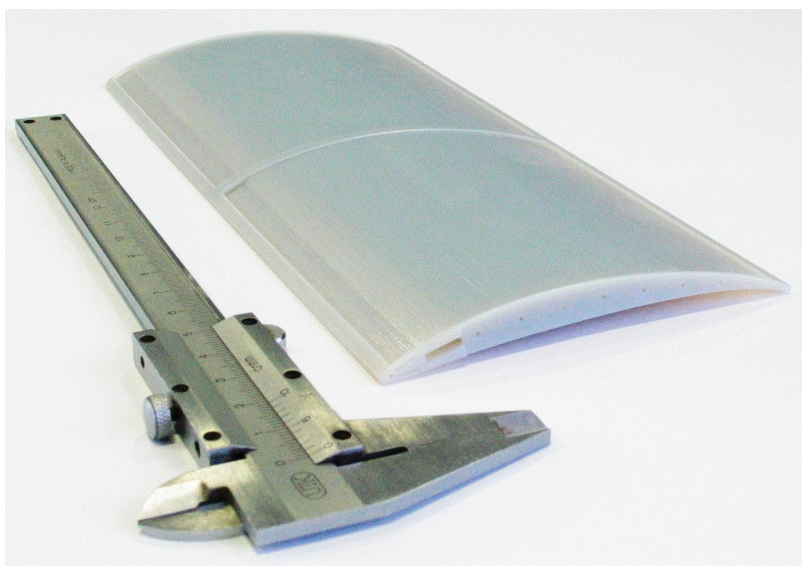

(a) Compressor blade manufactured in Poly Jet Modeling

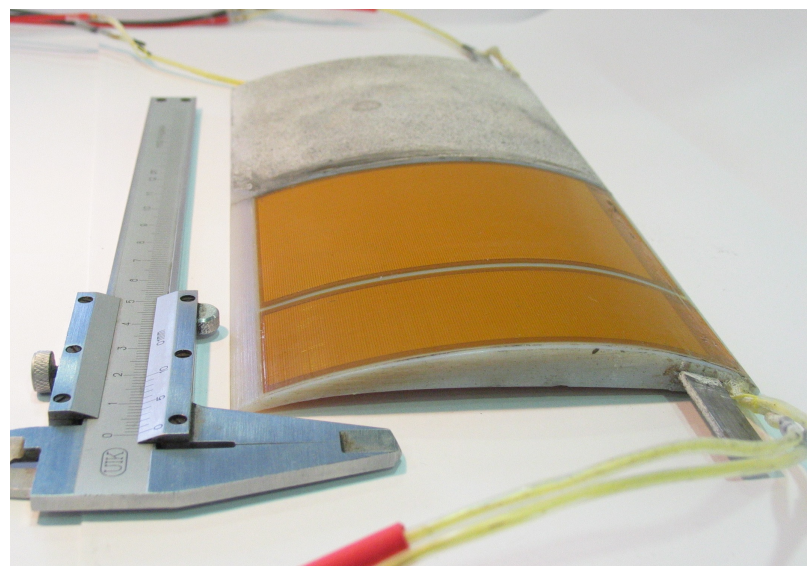

(b) Completely assembled compressor blade

Figure 4: Manufactured compressor blades

\section{Preliminary study to the actuators excitations}

To investigate the aerodynamic behaviour of the deformed blades static blade deformations with DC voltages applied to the actuators are required. Therefore in Riemenschneider et al.$^{7}$ different investigations with the manufactured blade were performed. In this study one objective was to characterize the behaviour of the combination of the blade material and actuators used under DC voltages. Another objective was to determine the voltages applied to the actuators to generate reproducible blade deformations. The investigations and the results are summarized shortly in this section.

By applying a negative DC voltage to the actuators Riemenscheider et al $!^{7}$ observed a drift at the blade's trailing edge over a measuring time of $900 \mathrm{~s}$. To minimize these effects first a reference run was executed. After the reference run is done a DC voltage was applied to the actuators. These investigations were performed with different voltage configurations. 
As a result a reference run is necessary before the actuators are applied with a maximum DC voltage of $U=1500 \mathrm{~V}$ and a minimum permitted $\mathrm{DC}$ voltage of $U=-400 \mathrm{~V}$. The reference run consists of a sinus wave with 15 oscillations, a period length of $10 \mathrm{~s}$, a peak to peak voltage of $U_{P P}=1900 \mathrm{~V}_{\mathrm{PP}}$ and an offset voltage of $U_{O f f}=550 \mathrm{~V}$. After the reference run is done the voltage signal changes into the DC voltages directly. With this reference run the influence of the voltages applied to the actuators before are minimized.

To avoid electrical failures at high actuator voltages, the actuators were applied with a maximum voltage of $1400 \mathrm{~V}$ in this study. Therefore the reference run has a peak to peak voltage of $1800 \mathrm{~V}$ and an offset voltage of $U_{O f f}=500 \mathrm{~V}$.

\section{Experimental wind tunnel investigations}

\section{A. Experimental setup}

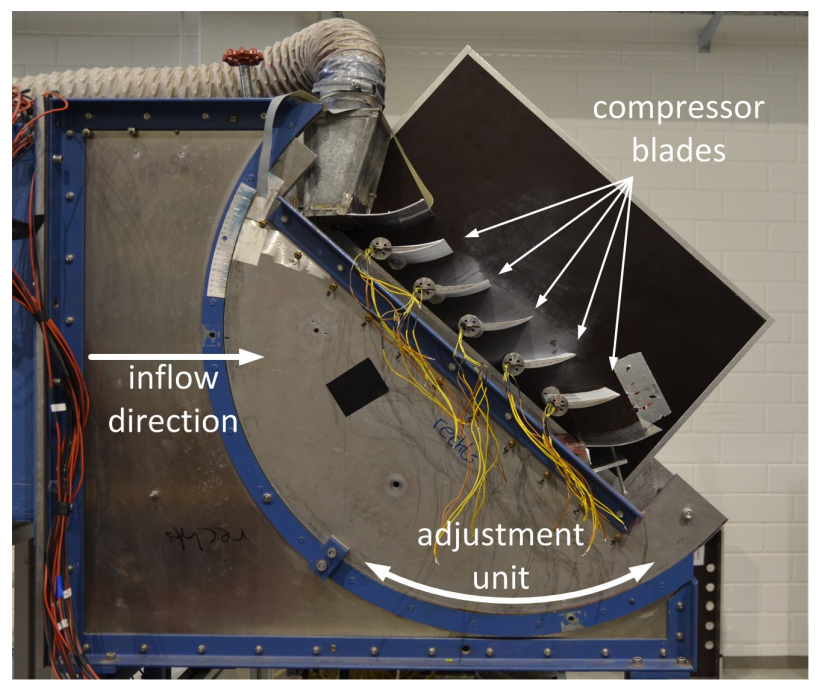

Figure 5: Cross section of the wind tunnel

In this section the experimental wind tunnel investigations are described. Therefore in figure 5 the wind tunnel setup is shown. The compressor blades were mounted as described in section IIT. The aerodynamic investigations are done by an inflow velocity of $v=44 \mathrm{~m} / \mathrm{s}$. The different angles of attack $\alpha_{25}=25^{\circ}$, $\alpha_{30}=30^{\circ}, \alpha_{35}=35^{\circ}, \alpha_{40}=40^{\circ}$ and $\alpha_{45}=45^{\circ}$ were adjusted with an adjustment unit which is shown in figure 5. The blade shapes in each state were measured with an optical measuring system (ATOS) using a fringe projection. With this system each blade condition was measured from different perspectives. This way nearly the whole blades surfaces can be measured. Only the area around to the leading edge can not be detected, which is not relevant for the quality of the measurements.

\section{B. Experimental procedure}

This section describes the procedure of the wind tunnel investigations. Therefore first the different blade shapes with the corresponding actuator voltages and the related reference run are described. In figure 6 an overview of the deformed and non-deformed shapes at the trailing edge of the middle blade and an angle of attack of $\alpha=35^{\circ}$ is shown.

To minimize the drift and the influence of the voltages applied the actuators in previous investigations the described reference run was executed for each shape. The reference run with the actuators at the suction and pressure side was performed synchronous with different phase shifts between them. The phase shift is used to control the DC voltage after the reference run is done and to control the various blade shapes defined in this section.

For each angle of attack various shapes were investigated. As a first step the undeformed shape with short-circuited actuators was investigated. This shape represents the blade shape used to adjust the wind tunnel configuration to generate a required periodical flow between the blades. This shape does not describe 


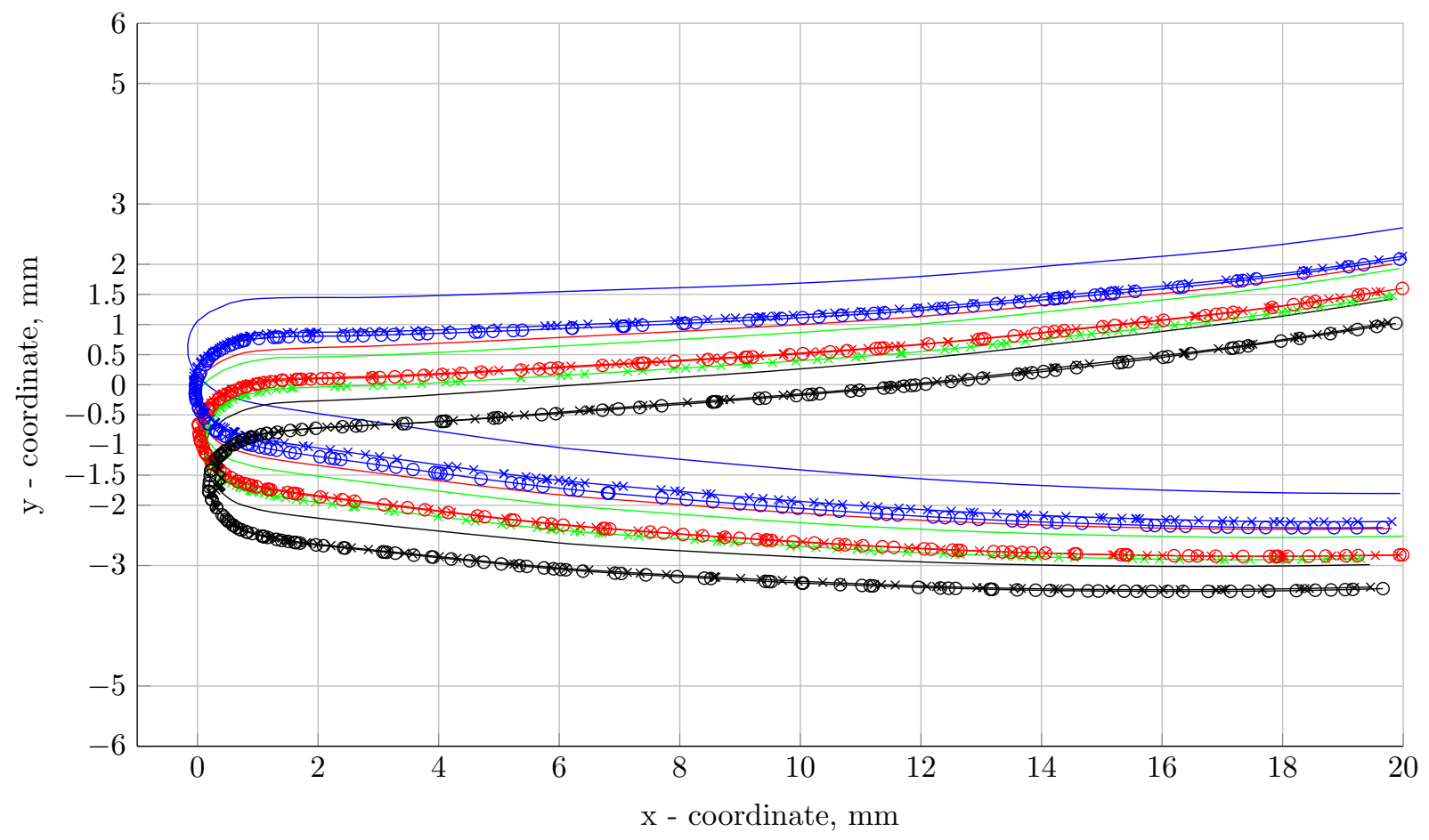

\begin{tabular}{|l|}
$-1 \mathrm{~A}$ - short-cuircuited shape without aerodynamic loads \\
- 1B - short-cuircuited shape with aerodynamic loads \\
$-2 \mathrm{~A}$ - zero position without aerodynamic loads \\
$-2 \mathrm{~B}$ - zero position with aerodynamic loads \\
$-2 \mathrm{C}$ - zero position with aerodynamic loads after aerodynamic measurements \\
$-3 \mathrm{~A}$ - deformation 1 without aerodynamic loads \\
$-3 \mathrm{~B}$ - deformation 1 with aerodynamic loads \\
$-3 \mathrm{C}$ - deformation 1 with aerodynamic loads after aerodynamic measurements \\
$-4 \mathrm{~A}$ - deformation 2 without aerodynamic loads \\
$-4 \mathrm{~B}$ - deformation 2 with aerodynamic loads \\
\hline
\end{tabular}

Figure 6: Overview of the different shapes with and without aerodynamic loads

the middle position between the maximum blade deformations. This has two causes. Firstly the actuators at the suction and pressure side do not have the same influence on the blade's deformation. Secondly the reference run is not performed, because of the short-circuited actuators. Following the influence of effects like different remanent strains induced by different applied voltages of previous investigations can not be minimized. In the following sections this shape is named short-circuited shape and has index 1 . In figure 6 this shape is described by green lines.

As next step the shape between the maximum blade deformations was investigated. Therefore the actuators were excited with a reference run with a phase shift of $0^{\circ}$ between the suction and pressure side actuators. After the 15 periods of the reference run are done a DC voltage of $500 \mathrm{~V}$ was applied to the suction and pressure side actuators. This position describes the middle position between the maximum blade deformations and is named zero position with index 2 . In figure 6 this shape is described by red lines.

As last step the two maximum blade deformations were investigated. Therefore first the shape with a DC voltage of $1400 \mathrm{~V}$ at the suction side and $-400 \mathrm{~V}$ at the pressure side was measured. This shape is named deformation 1 and has index 3 . In figure 6 this shape is described with blue lines. Thereafter the shape with a DC voltage of $-400 \mathrm{~V}$ at the suction side and $1400 \mathrm{~V}$ at the pressure side was measured. In the following this shape is named deformation 2 and has index 4 . In figure 6 this shape is described by black lines. In both cases the phase shift between the suction and pressure side actuators is $180^{\circ}$.

$$
8 \text { of } 13
$$




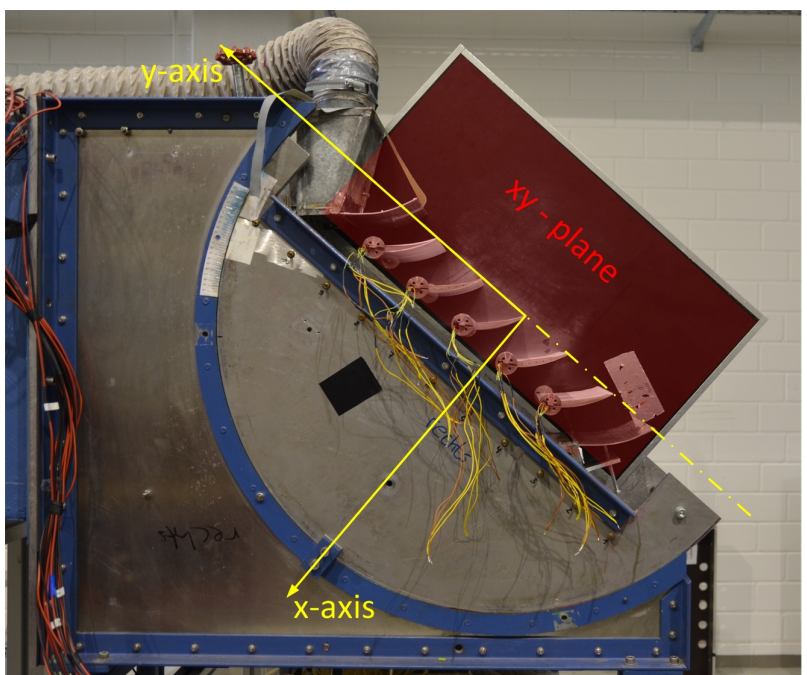

(a) Sketch of the coordinate system with the right but without the left wind tunnel wall.

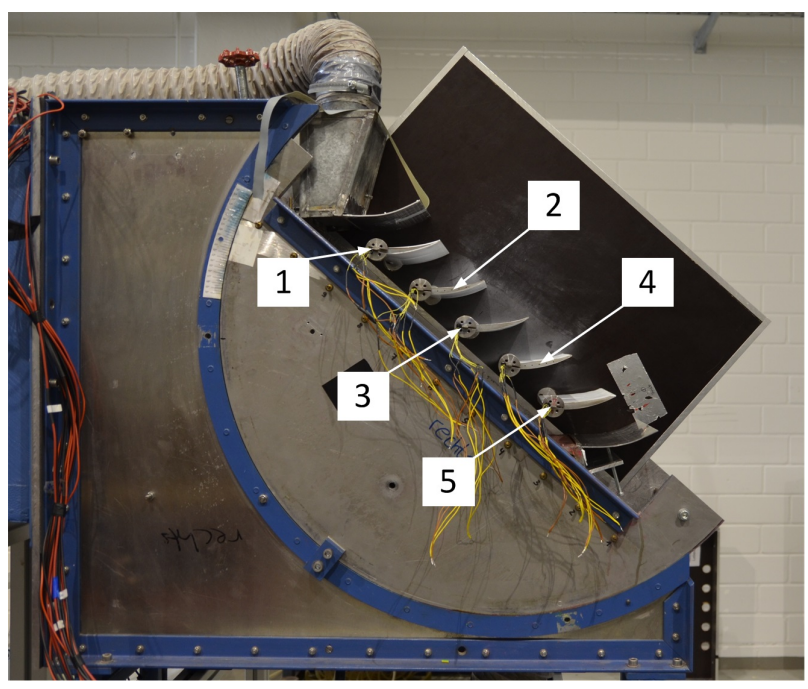

(b) Blade numbers

Figure 7: Wind tunnel setup with the right wind tunnel wall

Each shape is measured at three wind tunnel conditions. These conditions are described with the letters $\mathrm{A}, \mathrm{B}$ and $\mathrm{C}$. In condition A the shapes were measured without aerodynamic loads. In condition B the shapes were measured under aerodynamic loads. Then the aerodynamic measurements were performed in runs of approximately 45 minutes. To characterize the drift during the aerodynamic measurements another ATOS measurement under aerodynamic loads were performed after the aerodynamic measurements are done.

In summary all five blades were measured for each angle of attack in four shapes and in three wind tunnel conditions.

\section{Experimental results}

\section{Resulting blade deformations without aerodynamic loads}

In this section the maximum available blade deformations in mounted state at the wind tunnel are presented. As first step all measurements are transformed into the same coordinate system as shown in figure 7(a). The left wind tunnel wall represents the xy-plane (in figure 7(a) the xy-plane is projected onto the right wind tunnel wall). The y-axis is defined by the trailing edges of blade two and four. The trailing edge of blade three constitutes the coordinate origin.

In table 2 the averaged resulting blade displacements are given. The displacements are taken in the blades plane of symmetry at the trailing edge at the suction and pressure side for all angles of attack and each blade. Caused by the problem to measure the thin blade trailing edges correctly and following a lower measuring accuracy directly at the trailing edge the displacements are determined at the coordinate $x=3 \mathrm{~mm}$ before the trailing edge. To determine the maximum shape variation the displacement at the suction side with index $S S$ and the displacements at the pressure side with index $P S$ between the shapes $3 \mathrm{~A}$ and $2 \mathrm{~A}$ as well as $4 \mathrm{~A}$ and $2 \mathrm{~A}$ are calculated from the measurements. The equations are given in Eqs. (3) to (6).

$$
\begin{aligned}
& u_{S S_{3 A 2 A}}=P_{S S_{3 A}}-P_{S S_{2 A}} \\
& u_{S S_{4 A 2 A}}=P_{S S_{4 A}}-P_{S S_{2 A}} \\
& u_{P S_{3 A 2 A}}=P_{P S_{3 A}}-P_{P S_{2 A}} \\
& u_{P S_{3 A 2 A}}=P_{P S_{3 A}}-P_{P S_{2 A}}
\end{aligned}
$$

Comparing the displacements of the suction and pressure side a difference can be noted. This fact indicates a blade thickness variation or a blade drift caused by the behaviour of the actuator and material combination between the times the suction and the pressure sides were measured. The first case of a 
thickness variation can be excluded because the area around the coordinate $x=3 \mathrm{~mm}$ is a passive area without actuators. The second case will be discussed in section 2

Table 2: Resulting averaged blade displacements at the trailing edge for each blade

\begin{tabular}{|c|c|c|c|c|}
\hline & \multicolumn{2}{|c|}{ Suction side } & \multicolumn{2}{c|}{ Pressure side } \\
\hline blade number & $u_{S S_{3 A 2 A}} \backslash \mathrm{mm}$ & $u_{S S_{4 A 2 A}} \backslash \mathrm{mm}$ & $u_{P S_{3 A 2 A}} \backslash \mathrm{mm}$ & $u_{P S_{4 A 2 A}} \backslash \mathrm{mm}$ \\
\hline 1 & 0.986 & -0.880 & 0.995 & -0.916 \\
\hline 2 & 0.985 & -0.929 & 0.988 & -0.943 \\
\hline 3 & 0.848 & -0.861 & 0.835 & -0.880 \\
\hline 4 & 0.907 & -0.885 & 0.909 & -0.886 \\
\hline 5 & 0.836 & -0.744 & 0.795 & -0.779 \\
\hline
\end{tabular}

For the wind tunnel investigations a camber angle variation of $\Delta \varphi_{ \pm}=1^{\circ}$ was required. To verify whether this requirement can be fulfilled, the resulting blade outlet angle variation $\Delta \kappa_{2_{3 A 2 A}}=\kappa_{2_{3 A}}-\kappa_{2_{2 A}}$ between the shapes $3 \mathrm{~A}$ and $2 \mathrm{~A}$ as well as $\Delta \kappa_{2_{4 A 2 A}}=\kappa_{2_{4 A}}-\kappa_{2_{2 A}}$ between $4 \mathrm{~A}$ and $2 \mathrm{~A}$ in the blade's plane of symmetry were calculated for blade number three. Therefore the surface points at $x=3 \mathrm{~mm}$ and $x=5 \mathrm{~mm}$, the slope between them and as next step the outlet angle to the $\mathrm{x}$-axis at the suction and pressure side were determined. Under the assumption of a fixed non-deformable blade leading edge finally the camber angle variation $\Delta \varphi=\Delta \kappa_{2_{4 A 2 A}}-\Delta \kappa_{2_{3 A 2 A}}$ is calculated. The results are given in table 3. It can be seen that the required camber angle variation of $\Delta \varphi \pm 1^{\circ}$ can be fulfilled. With this angle variation and the displacements of the other blades the angle variation of all shapes and of all blades can be estimated.

Table 3: Resulting averaged angle variation at the trailing edge of blade three

\begin{tabular}{|c|c|c|}
\hline & Suction side & Pressure side \\
\hline$\Delta \kappa_{2_{3 A 2 A}}$ & $-1.001^{\circ}$ & $-0.921^{\circ}$ \\
\hline$\Delta \kappa_{2_{4 A 2 A}}$ & $1.239^{\circ}$ & $1.115^{\circ}$ \\
\hline$|\Delta \varphi|$ & $2.240^{\circ}$ & $2.036^{\circ}$ \\
\hline
\end{tabular}

Similar to the results of displacements in table 2 the results of the camber angle variation at the suction and pressure side are different. This can be justified with the drift between the moments the suction and the pressure sides were measured, too.

\section{Results under aerodynamic loads}

In this section the results of the blade displacements of blade 3 are presented. The results are taken from the plane of symmetry at $x=3 \mathrm{~mm}$ between the shapes without aerodynamic loads to the corresponding shapes under aerodynamic loads. Therefore in figure 8 the displacements at the suction and in figure 9 the displacements at the pressure side are shown. The given displacements of the suction side are calculated with the following equations equivalent to the nomenclature of Eqs. (3) to (6):

$$
\begin{aligned}
& u_{S S_{1 B 1 A}}=P_{S S_{1 B}}-P_{S S_{1 A}} \\
& u_{S S_{2 B 2 A}}=P_{S S_{2 B}}-P_{S S_{2 A}} \\
& u_{S S_{2 C 2 A}}=P_{S S_{2 C}}-P_{S S_{2 A}} \\
& u_{S S_{3 B 3 A}}=P_{S S_{3 B}}-P_{S S_{3 A}} \\
& u_{S S_{3 C 3 A}}=P_{S S_{3 C}}-P_{S S_{3 A}} \\
& u_{S S_{4 B 4 A}}=P_{S S_{4 B}}-P_{S S_{4 A}} \\
& u_{S S_{4 C 4 A}}=P_{S S_{4 C}}-P_{S S_{4 A}}
\end{aligned}
$$


The displacements of the pressure side are calculated similar to the displacements of the suction side. In both diagrams a similar behaviour can be seen. The displacements decreases from lower angles of attack to higher angles of attack. In a first approximation the curves of each shape can be described with a regression line. The calculated slope of the regression line is given at the legend of the figures, too.

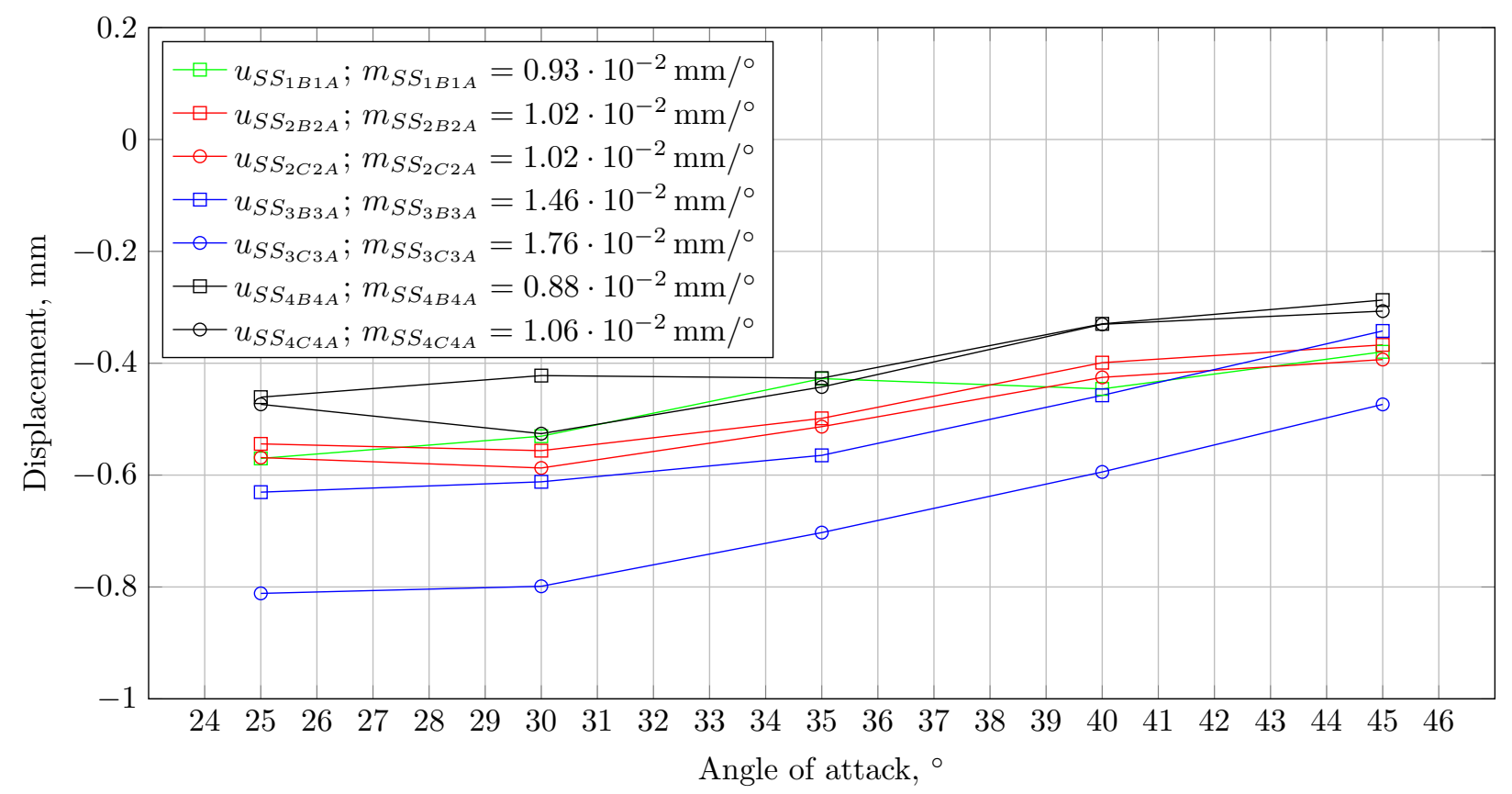

Figure 8: Trailing edge displacement at the suction side at different angles of attack for blade 3

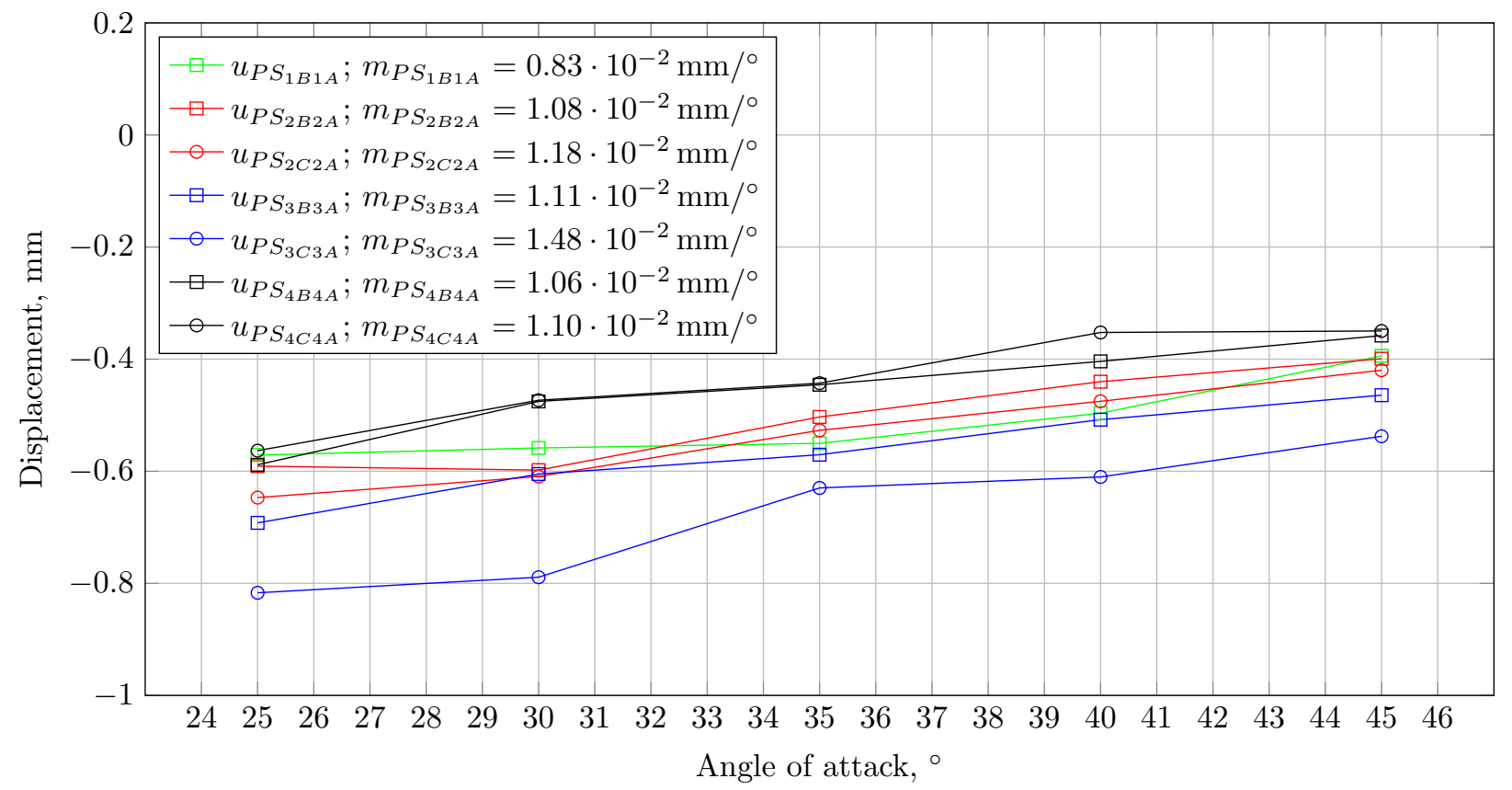

Figure 9: Trailing edge displacement at the pressure side at different angles of attack for blade 3

Similar to the results in section 1 a comparison between the displacements at the suction and pressure side shows different results. Due to this fact the differences $\delta$ between the displacements of the suction and 


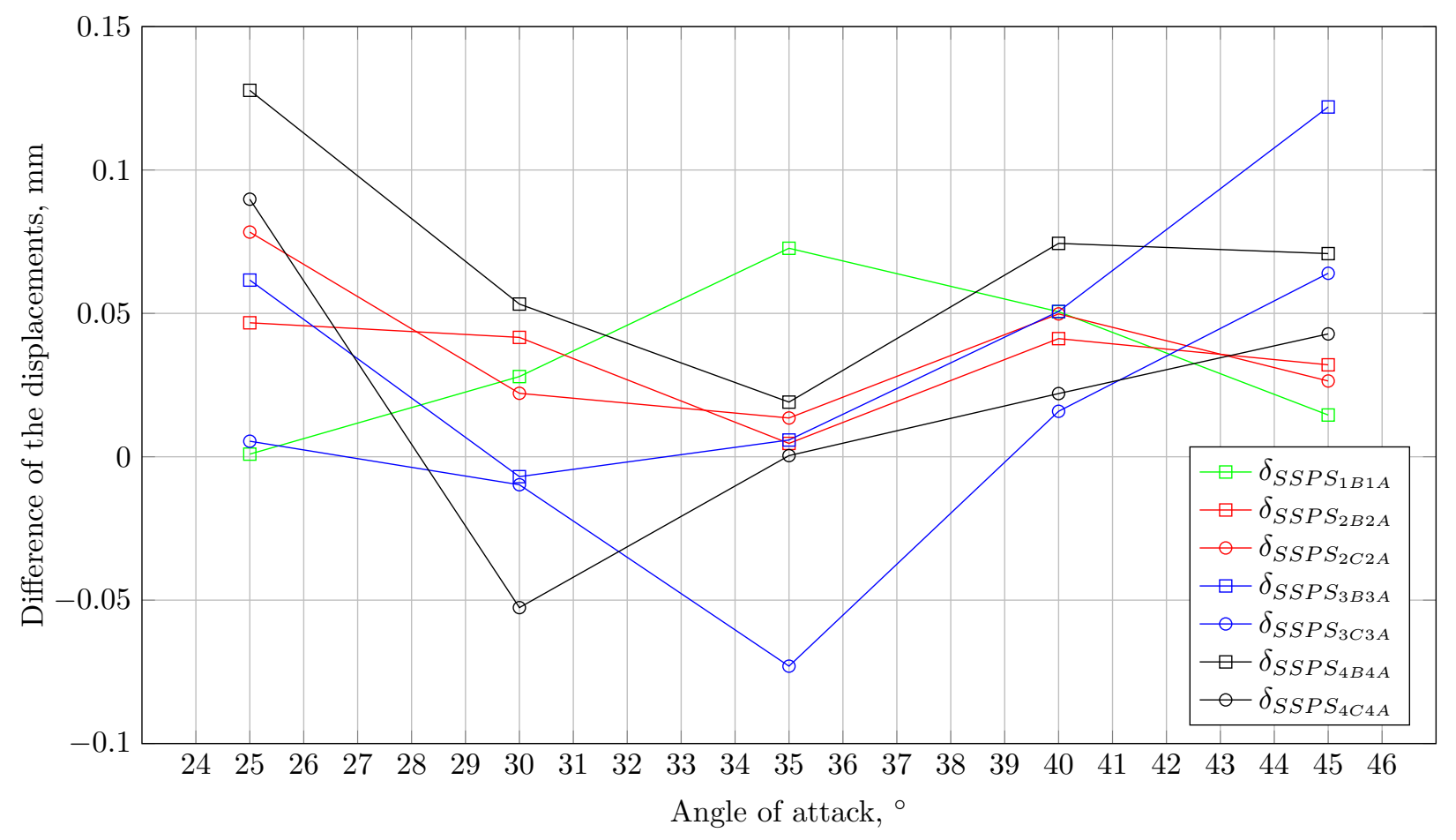

Figure 10: Difference of the trailing edge displacements at different angles of attack for blade 3

pressure side are shown in figure 10. The differences are calculate with Eqs. (14) to 200:

$$
\begin{aligned}
& \delta_{S S P S_{1 B 1 A}}=u_{S S_{1 B 1 A}}-u_{P S_{1 B 1 A}} \\
& \delta_{S S P S_{2 B 2 A}}=u_{S S_{2 B 2 A}}-u_{P S_{2 B 2 A}} \\
& \delta_{S S P S_{2 C 2 A}}=u_{S S_{2 C 2 A}}-u_{P S_{2 C 2 A}} \\
& \delta_{S S P S_{3 B 3 A}}=u_{S S_{3 B 3 A}-u_{P S_{3 B 3 A}}} \\
& \delta_{S S P S_{3 C 3 A}}=u_{S S_{3 C 3 A}}-u_{P S_{3 C 3 A}} \\
& \delta_{S S P S_{4 B 4 A}}=u_{S S_{4 B 4 A}}-u_{P S_{4 B 4 A}} \\
& \delta_{S S P S_{4 C 4 A}}=u_{S S_{4 C 4 A}}-u_{P S_{4 C 4 A}}
\end{aligned}
$$

The differences have three main causes. First cause is a drift by applying the actuators with a DC voltage. The second cause can be a non-linear behaviour of the blade material due to creep. Both causes are time dependent and are minimized with the preliminary studies and the resulting experimental procedure described in section III, but can not be excluded completely. As third cause the measuring time needed to measure the surfaces of all blades can be identified. In order to measure one shape an average time of 29 minutes was required. The maximum and the minimum period of time needed to measure one shape were 56 respectively 14 minutes. This means that the blade's suction and pressure sides were measured in different time intervals.

Ideally the difference $\delta$ between the suction and the pressure side is $\delta=0 \mathrm{~mm}$. Due to the facts that were described before this requirement can not be fulfilled. Consequently the difference can be used to estimate the measurement accuracy of the whole measuring process. The arithmetic average of the calculated differences is $\bar{\delta} \approx 0.035 \mathrm{~mm}$ and the standard deviation is $s \approx 0.041 \mathrm{~mm}$. With the arithmetic average, the standard deviation, a student factor of $t \approx 2.728$ for $n=35$ (number of measurements) and a confidence level of $P_{C}=99 \%$ as well as the assumption of a normal distribution the confidence interval for each measuring 
point can be estimated with Eq. 21] taken from Grote.

$$
\begin{aligned}
& P_{i}= \pm \frac{t \cdot s}{\sqrt{n}}= \pm \frac{2.728 \cdot 0.041 \mathrm{~mm}}{\sqrt{35}} \\
& P_{i} \approx \pm 0.019 \mathrm{~mm}
\end{aligned}
$$

Comparing the calculated confidence interval in Eq. 21) with the total overall blade displacements of blade $3 u_{S S, t o t}=u_{S S_{3 A 2 A}}-u_{S S_{4 A 2 A}}=1.709 \mathrm{~mm}$ and $u_{P S, t o t}=u_{P S_{3 A 2 A}}-u_{P S_{4 A 2 A}}=1.715 \mathrm{~mm}$ according to the displacements in table 2 the relative deviations can be calculated as follows:

$$
\begin{aligned}
f_{S S} & =\frac{P_{i}}{u_{S S, t o t}}=\frac{0.019 \mathrm{~mm}}{1.709 \mathrm{~mm}} \cdot 100 \% \\
f_{S S} & \approx \underline{\underline{1.112 \%}} \\
f_{P S} & =\frac{P_{i}}{u_{P S, t o t}}=\frac{0.019 \mathrm{~mm}}{1.715 \mathrm{~mm}} \cdot 100 \% \\
f_{P S} & \approx \underline{\underline{1.108 \%}}
\end{aligned}
$$

The calculated relative deviations are low. Therefore the experimental data can also be used for a validation of CFD simulations.

\section{Conclusion}

In this paper first results of a cascaded wind tunnel test with 5 shape adaptive compressor blades were presented, focusing on the blade displacements at the trailing edge of the blade in the middle. The resulting blade deformation of the blade in the middle has a maximum blade displacement of $\Delta u=1.715 \mathrm{~mm}$ respectively a maximum camber angle variation of $\Delta \varphi=2.240^{\circ}$. The influence of the aerodynamic loads to the blades displacements could be shown. The measurement accuracy for the whole measuring process was estimated.

Due to the low relative deviations between the measurements, in the next step the behaviour of the whole structure with and without aerodynamic loads will be analysed. In addition the aerodynamic measurements, for example the pressure distributions, have to be analysed, too. Finally the real surfaces of the measured blades in mounted state in the wind tunnel can be used to validate CFD simulations.

In this study the structural feasibility of morphing compressor blades under aerodynamic loads could be demonstrated. Assuming the aerodynamic results are promising, too, the next step is to transfer this concept to a three dimensional compressor blade.

\section{References}

\footnotetext{
${ }^{1}$ Müller, T., Lawerenz, M., Shape adaptive airfoils for turbomachinery applications undergoing large deformations, 44th AIAA/ASME/ASCE/AHS Structures, Structural Dynamics, and Maeterials Conference Norfolk, 2003.

${ }^{2}$ Müller, T., Entwicklung und experimentelle Untersuchung einer formvariablen Turbomaschinenschaufel, FortschrittBerichte VDI, Vol. 7, Nr.482, VDI Verlag, 2006.

${ }^{3}$ Müller, T., Lawerenz, M., Numerische Simulation formvariabler Strukturkonzepte axialer Eintrittsleiträder von Turboverdichtern, 3. LS-DYNA Anwenderforum Bamberg, 2004.

${ }^{4}$ Monner, H.P., Realization of an optimized wing camber by using formvariable flap structures, Aerospace Science and Technology, Vol. 5, No. 7, 1270-9638, 2001.

${ }^{5}$ Van de Kamp, B., Konzeptstudie: Strukturkonzept adaptiver Beschaufelungen für Turbofan-Triebwerke, Diploma Thesis, Braunschweig, 2012.

${ }^{6}$ Wittel, H.; Muhs, D.; Jannasch, D. and Voßiek, J., Roloff/Matek Maschinenelemente: Tabellenbuch, 19th edition, Vieweg + Teubner Verlag, 2009

${ }^{7}$ Riemenschneider, J., Huxdorf, O., Opitz, S., Effects of Piezoceramic Actuator in Quasistatic Use, ASME International Conference on Smart Materials, Adaptive Structures and Intelligent Systems Newport, Rhode Island, 2014.

${ }^{8}$ Grote, K.-H., Feldhusen, J., Dubbel: Taschenbuch für den Maschinenbau, 22th edition, Springer, 2007

${ }^{9}$ Objet: FullCureßMaterials. data sheet, URL: http : //svl.wpi.edu/wp-content/uploads/2014/04/FullCure_Letter_low1.pdf, nov. 2014 .
} 